\title{
Changes in Glial Cell Line-derived Neurotrophic Factor Expression in the Rostral and Caudal Stumps of the Transected Adult Rat Spinal Cord
}

\author{
Hao-Li Zhou · Hui-Juan Yang · Yong-Mei Li · Ying Wang · Ling Yan · \\ Xi-Liang Guo $\cdot$ Ying-Chun Ba $\cdot$ Su Liu $\cdot$ Ting-Hua Wang
}

Published online: 5 August 2008

(C) Springer Science+Business Media, LLC 2008

\section{Erratum to: Neurochem Res}

\section{DOI 10.1007/s11064-007-9536-1}

Please be advised that subsequent to the publication of the article copyright was transferred to Springer Science+ Business Media, LLC.

The online version of the original article can be found under doi:10.1007/s11064-007-9536-1.

H.-L. Zhou · T.-H. Wang Institute of Neurological Disease, West China Hospital,

Sichuan University, Chengdu 610041, China

H.-L. Zhou · H.-J. Yang · Y.-M. Li · L. Yan · X.-L. Guo ·

Y.-C. Ba $\cdot$ S. Liu $\cdot$ T.-H. Wang ( $₫)$

Institute of Neuroscience, Kunming Medical College,

Kunming 650031, China

e-mail: tinghua_neuron@263.net

Y. Wang

Nursing Department, Weifang Medical College,

Weifang 261042, China

T.-H. Wang

Department of Histology, Embryology and Neurobiology, College of Preclinical and Forensic Medicine,

Sichuan University, Chengdu 610041, China 